\title{
A SIMPLIFIED METHOD FOR SEISMIC PERFORMANCE EVALUATION OF STEEL BRIDGE PIERS WITH THIN-WALLED STIFFENED BOX SECTIONS
}

\author{
Jiandong Zhang ${ }^{1,2}$, Chun-Lin Wang ${ }^{1}$ and Hanbin $\mathrm{Ge}^{1,3^{*}}$ \\ ${ }^{1}$ International Institute for Urban Systems Engineering, Southeast University, Sipailou 2, Nanjing 210096, China \\ ${ }^{2}$ Jiangsu Transportation Research Institute Co., Ltd, Nanjing, 210017, China \\ ${ }^{3}$ Department of Civil Engineering, Meijo University, Tempaku-ku, Nagoya 468-8502, Japan \\ *(Corresponding author: E-mail: gehanbin@meijo-u.ac.jp)
}

Received: 28 September 2012; Revised: 22 December 2012; Accepted: 27 December 2012

\begin{abstract}
This paper proposes a simplified seismic evaluation method for the thin-walled stiffened box steel pier to predict its strength and ductility. In this method, two modified bilinear material models for the fiber-beam element are suggested to include the local buckling of the base stiffened plate. An experiment validated a shell element based model, which was selected for comparison with the proposed fiber-beam based model. Twelve numerical cases were then simulated by the shell element based model and the fiber-beam element based model, respectively, and their accuracies were compared with each other. Numerical results showed that the proposed pushover method, employing the amended bilinear kinematic material model for the fiber beam element, is of good accuracy. If the maximum strength is taken as the ultimate point, the bilinear material model, replacing the yield point by the buckling stress, is recommended. If 95 percent of the maximum strength after the peak is regarded as the ultimate point, the elastic-perfectly plastic material model is suggested.
\end{abstract}

Keywords: Steel Bridge, Seismic Evaluation Method, Stiffened Box Section, Fiber Element

\section{INTRODUCTION}

Cantilever-type steel columns of thin-walled box sections are widely used as bridge piers in urban area. Up to now, investigations on the strength and ductility of thin-walled steel bridge piers under cyclic and dynamic loading have been extensively carried out for evaluating their seismic performance, and a great deal of knowledge has been achieved (e.g. Usami and Ge [1], Ge et al. [2], Usami et al. [3], Susantha et al. [4]). The local and overall interaction buckling of the thin-walled stiffened steel piers is regarded as one reason for the failure during the earthquake (Galambos [5]). Many researchers used the finite-element (FE) based analysis to predict the hysteretic behavior and failure modes of the thin-walled steel members under cyclic loading (e.g. Gao et al. [6], Goto et al. [7]). Although the FE numerical approaches, employing the shell elements, can accurately simulate the buckling of the thin-walled box member, as given in the literature (Ge et al. [2]), the FE models included the complex element grids, whose sizes remarkably affected the results. Besides, the FE model building is a complicated and time-consuming process, which cannot be accepted and popular for normal designers in engineering practice.

A relatively simplified evaluation method, instead of the time-consuming shell element based simulation, is very urgent in the case that the thin-walled box members are applied in the structural design. Sakimoto et al. [8] proposed a new stress-strain relation for the fiber-beam based simulation of the thin-walled box member. This average stress-strain relationship was obtained from the shell element based simulation and included the effect of the stiffened plate's local buckling. Therefore, it exhibited a strain softening behavior and can be described as a function of a slenderness parameter of the stiffened plate. However, numerical results were susceptible to the size of the element because of its strain-softening behavior. Afterwards, a buckling element with a finite length was introduced in order to avoid the strain concentration in the small softening element by Ozawa 
et al. [9]. Numerical examples confirmed that the pushover analysis with the new nonlinear beam element can predict the ultimate behavior of the steel piers. However, it is not easy for engineers to use in practical design because the proposed model equation has 36 coefficients without giving their values in the paper and the applicable range is limited (e.g., the width-thickness ratio parameter as shown later in Eq .1 is from 0.3-0.5).

In this paper, taking into account the local buckling of the thin-walled steel stiffened plate, the characteristics of the bilinear material model was modified. First, the comparison of a shell element based simulation with an experiment showed the effectiveness of the shell element based model. Second, a simplified pushover method based on the fiber-beam element in which the material model included the effect of the stiffened plate's local buckling was proposed. Furthermore, the predicted ultimate load-carrying capacities of the thin-walled steel box piers were compared between the proposed method and the shell element based simulation.

\section{VERIFICATION OF SHELL-ELEMENT BENCHMARK MODEL}

\subsection{Specimen Configuration}

A cantilever steel column with uniform square cross section, subjected to a constant axial force and cyclic lateral loading, was given in the literature (Nishikawa et al. [10]). As shown in Figure 1, this column was stiffened by both longitudinal stiffeners and diaphragms. In the present study, the test results of the No.4 specimen (Nishikawa et al. [10]) are employed to calibrate the shell element based simulation. Its geometrical dimensions and material properties are listed in Tables 1 and 2.

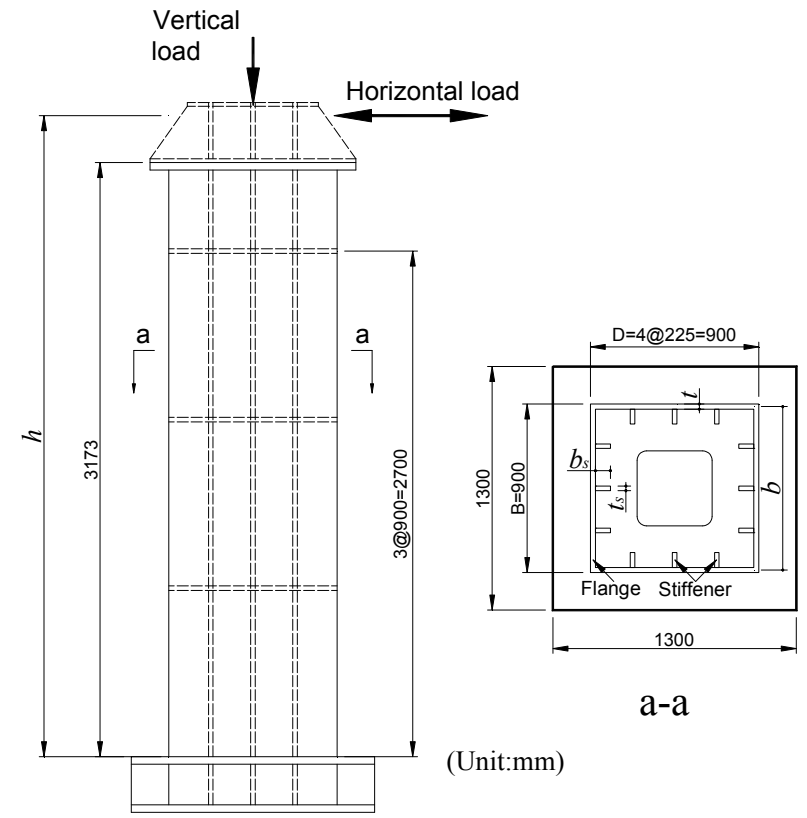

Figure 1. Test Specimen with Box Cross Section (Nishikawa et al. [10])

Table 1. Geometrical Parameters of Specimen

\begin{tabular}{ccccccccccc}
\hline$h(\mathrm{~mm})$ & $b(\mathrm{~mm})$ & $t(\mathrm{~mm})$ & $b_{s}(\mathrm{~mm})$ & $t_{s}(\mathrm{~mm})$ & $R_{f}$ & $\bar{\lambda}$ & $\gamma / \gamma^{*}$ & $\alpha$ & $\overline{\lambda_{s}}$ & $P / P_{y}$ \\
\hline 3403 & 891 & 9.1 & 80 & 6.2 & 0.56 & 0.26 & 0.89 & 1.0 & 0.63 & 0.122 \\
\hline
\end{tabular}


Table 2. Material Properties of Specimen

\begin{tabular}{cccc}
\hline$\sigma_{y}(\mathrm{MPa})$ & $\begin{array}{c}E \\
(\mathrm{GPa})\end{array}$ & $v$ & $E / E_{s t}$ \\
\hline 379 & 206 & 0.3 & 100 \\
\hline
\end{tabular}

In Table 1 , the flange plate width-thickness ratio $\left(R_{f}\right)$ and the column slenderness ratio parameter $(\bar{\lambda})$ are the two important parameters, which control the inelastic cyclic behavior of the steel box columns. The former parameter inhibits the local buckling of the flange plate, while the latter determines the global instability. They are given as,

$$
\begin{aligned}
& R_{f}=\frac{b}{t} \sqrt{\frac{12\left(1-v^{2}\right)}{\pi^{2} k}} \sqrt{\frac{\sigma_{y}}{E}} \\
& \bar{\lambda}=\frac{2 h}{r} \frac{1}{\pi} \sqrt{\frac{\sigma_{y}}{E}}
\end{aligned}
$$

where, $t$ is the plate thickness, $b$ the flange plate width $=B-t$ ( $B$ is the width of the cross section), $\sigma y$ the yield stress, $v$ the Poisson's ratio, $E$ the Young's modulus, $k$ the buckling coefficient of a stiffened plate $=4 n^{2}$ ( $n$ is the number of subpanels in each stiffened plate), $h$ the column height and $r$ the radius of gyration of cross section.

The stiffener's slenderness ratio, $\bar{\lambda}_{s}$, affects the deformation capacity of stiffeners and local buckling mode. It can be given as (Ge et al. [2]),

$$
\begin{aligned}
& \bar{\lambda}_{s}=\frac{1}{\sqrt{Q}} \frac{L_{d}}{r_{s}} \frac{1}{\pi} \sqrt{\frac{\sigma_{y}}{E}} \\
& Q=\frac{1}{2 R_{f}}\left(\beta-\sqrt{\beta^{2}-4 R_{f}}\right) \leq 1.0
\end{aligned}
$$

$\beta=1.33 R_{f}+0.868$

where $L_{d}$ is the distance between two adjacent diaphragms, $r_{\mathrm{s}}$ the radius of gyration of T-shape cross-section centered on one longitudinal stiffener with its width of $b / n$; and $Q$ the local buckling strength of a plate enclosed by two adjacent diaphragms and stiffeners. Moreover, in Table $1, \gamma$ is the relative flexural rigidity of one stiffener and $\gamma^{*}$ is the optimum value of $\gamma$ obtained from the linear buckling theory; $\alpha\left(=L_{d} / \mathrm{B}\right)$ is the aspect ratio of the flange plate between two diaphragms; $P / P_{y}$ is the magnitude of axial load; $b_{s}$ the width of stiffener; and $t_{s}$ the thickness of the stiffener.

\subsection{Shell Element-based Model}

During the 1995 Hyogoken-Nanbu earthquake, for such thin-walled steel columns, the local buckling occurred near the base of the columns. Therefore, as shown in Figure 2, the beam element is employed for the upper portion of the column, while the shell element, which can consider the effect of the local buckling, is used for the lower portion of the column. For the part of shell elements, the length from the base to the first diaphragm is divided into 9 segments and the subsequent same lengths are divided into 5 segments along the column length. The length and width of the cross section are divided into 12 segments, respectively. The longitudinal stiffener and 
the diaphragm are also simulated with the shell elements. On the other hand, 10 beam elements are adopted to model the upper part of the column. Taking advantage of the symmetry of the geometry, the loading and the boundary of the specimen within the test plane, only half of the column is simulated. Besides, a stiff plate with infinite bending stiffness is assumed in the interface between the beam-element part and the shell-element part, where the third diaphragm is located.

In this simulation, both material and geometrical nonlinearities are considered. As shown in Figure 3(a), the bilinear elastic-plastic material model is employed to model the plastic deformation. As the name suggests this model used two lines to represent the stress-strain curve: the slope of the first line is the initial Young's modulus, $E$; and the slope of the second line is the post-yield modulus, $E_{s t}$, which is set as $E / 100$ in this study. Furthermore, the bilinear kinematic hardening is used as the hardening rule, as shown in Figure 3(b).

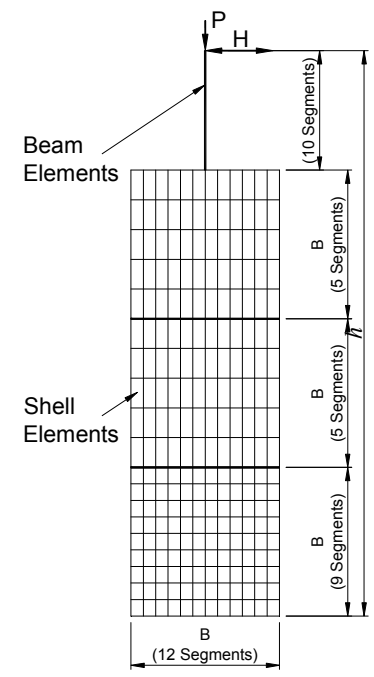

Figure 2. Analytical Model of Steel Box Bridge Pier

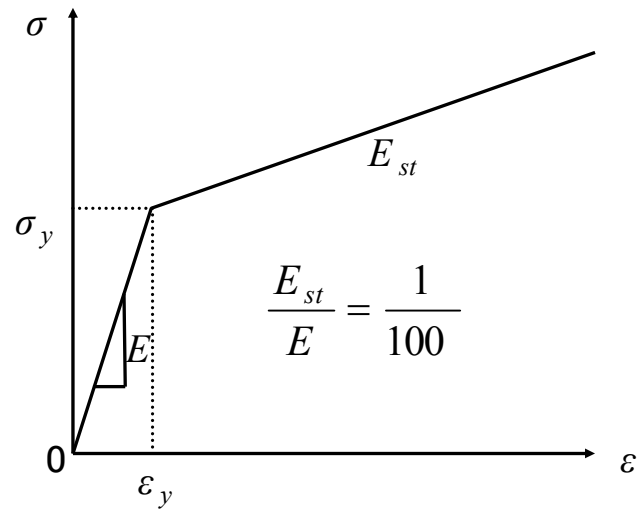

(a)

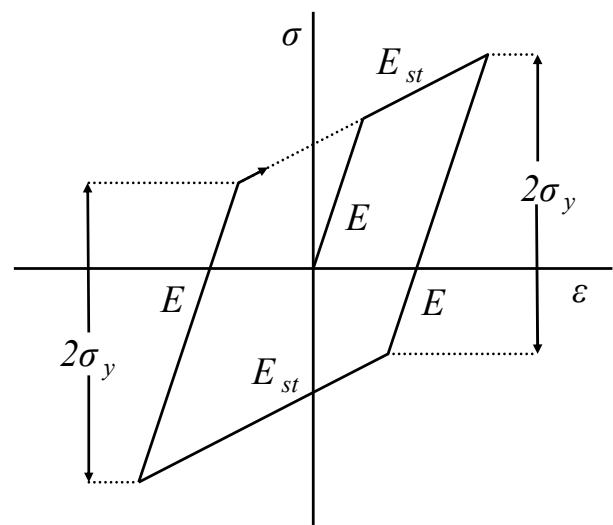

(b)

Figure 3. Stress-strain Behavior of Steel Material

\subsection{Comparison between Simulation and Experiment}

At the beginning of the test, a constant force, $P$, was applied on the top of the steel column. Subsequently, a cyclic loading pattern controlled by the imposed lateral displacement was used to conduct this experiment. As shown in Figure 4, the lateral displacement history consists of 
sequence of full reversed displacement cycles and the peak displacements are increased stepwise with the increment, $\delta_{y}$, after one cycle at each displacement level.

The lateral load versus lateral displacement hysteretic curve of the column obtained from the simulation is plotted with the test results (see Figure 5). After obtaining the load-displacement curve, the yield lateral load, $H_{y}$, and the yield lateral displacement, $\delta_{y}$, will be employed to non-dimensionalize the curves. Here, $H_{y}$ is taken as the smaller one from the following two equations (Usami et al. [11]),

$$
\begin{aligned}
& H_{y}=\frac{M_{y}}{0.85 h}\left(1-\frac{P}{P_{E}}\right)\left(1-\frac{P}{P_{u}}\right) \\
& H_{y}=\frac{M_{y}}{h}\left(1-\frac{P}{P_{y}}\right)
\end{aligned}
$$

where $M_{y}$ is the yield moment of cross section, $P_{E}$ the Euler's buckling loading of a cantilever column and $P_{u}$ the ultimate strength of a centrally loaded column, which is determined from the following equation adopted in the Japanese specification for road bridges [12].

$$
\frac{P_{u}}{P_{y}}=\left\{\begin{array}{lc}
1.0 & (\bar{\lambda} \leq 0.2) \\
1.109-0.545 \bar{\lambda} & (0.2 \leq \bar{\lambda} \leq 1.0) \\
1 /\left(0.773+\bar{\lambda}^{2}\right) & (\bar{\lambda} \geq 1.0)
\end{array}\right.
$$

The yield displacement, $\delta_{y}$, is then calculated from the following equation neglecting transverse shear deformation:

$\delta_{y}=\frac{H_{y} h^{3}}{3 E I}$

It can be seen that the strengths predicted by the shell element based model at each reversal point are quite close to the test results, that is to say, this model can excellently reflect the steel pier with the thin-walled stiffened box cross section. Therefore, this shell element based approach is used as the benchmark model to validate the proposed fiber-beam element based method in the following sections.

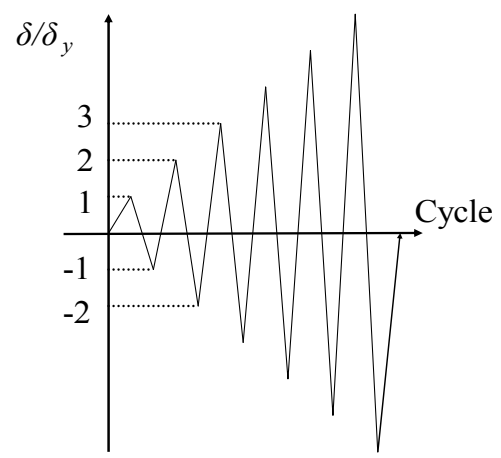

Figure 4. Lateral Displacement History

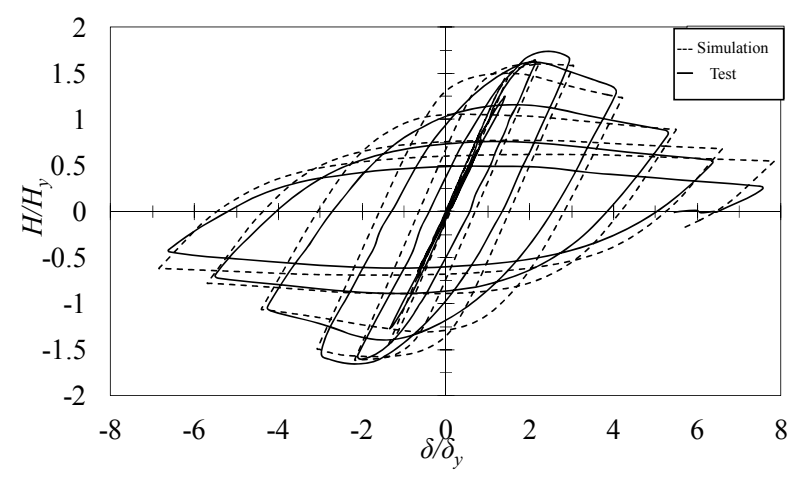

Figure 5. Comparison of Hysteretic Curves 


\section{$2.4 \quad$ Numerical Cases}

In order to compare the shell element based model with the beam element based model (i.e., the fiber model), twelve numerical cases of the thin-walled stiffened box piers were analyzed. The main parameters considered are: flange plate width-thickness ratio $R_{f}$, column slenderness ratio $\bar{\lambda}$, stiffener's slenderness ratio $\bar{\lambda}_{s}$. The scope of these parameters are $R_{\digamma}=0.5 \sim 0.8, \bar{\lambda}=0.3 \sim 0.5$ and $\bar{\lambda}_{s}=0.534 \sim 0.935$, respectively. Table 2 lists geometrical properties of numerical cases and Figure 6 (a) plotted their cross sections. The material properties of these cases are $\sigma_{y}=314 \mathrm{MPa}, E=206 \mathrm{GPa}$ and $v=0.3$. As shown in Figure 6(b), the same shell element based analysis method and loading pattern were employed in this simulation.

Figure 7 shows hysteretic curves of non-dimensionalized lateral load, $H / H_{y}$, versus lateral displacement, $\delta / \delta y$. It can be concluded that both the strength and ductility slightly decrease with the increase in $\bar{\lambda}$. On the other hand, the maximum strength obviously decreases with the increase in $R_{f}$.

(a)

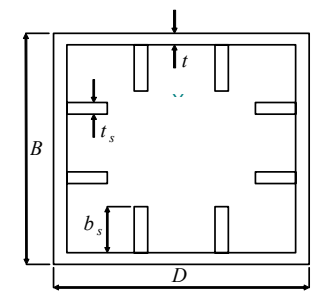

(b)

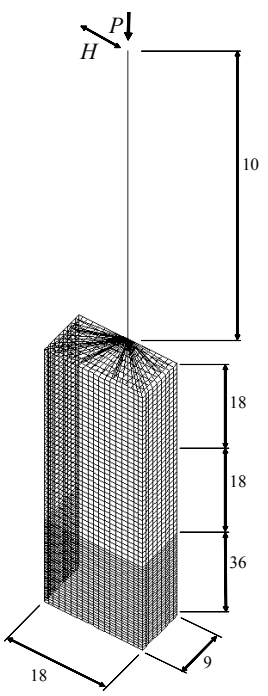

Figure 6. Shell Element Based Model of Numerical Cases

Table 3 Geometrical Dimensions and Parameters of Numerical Cases

\begin{tabular}{cccccccccccccc}
\hline No. & $\begin{array}{c}h \\
(\mathrm{~mm})\end{array}$ & $\begin{array}{c}b \\
(\mathrm{~mm})\end{array}$ & $\begin{array}{c}t \\
(\mathrm{~mm})\end{array}$ & $\begin{array}{c}b_{s} \\
(\mathrm{~mm})\end{array}$ & $\begin{array}{c}t_{s} \\
(\mathrm{~mm})\end{array}$ & $R_{f}$ & $\bar{\lambda}$ & $\gamma / \gamma^{*}$ & $\alpha$ & $\overline{\lambda_{s}}$ & $P / P_{y}$ & $\begin{array}{c}H_{y} \\
(\mathrm{kN})\end{array}$ & $\begin{array}{c}\delta_{\mathrm{y}} \\
(\mathrm{mm})\end{array}$ \\
\hline S1 & 7025 & 1461 & 20 & 133 & 20 & 0.5 & 0.3 & 1.0 & 1.0 & 0.53 & 0.17 & 2242 & 30.2 \\
S2 & 9366 & 1461 & 20 & 133 & 20 & 0.5 & 0.4 & 1.0 & 1.0 & 0.53 & 0.13 & 1760 & 53.4 \\
S3 & 11708 & 1461 & 20 & 133 & 20 & 0.5 & 0.5 & 1.0 & 1.0 & 0.53 & 0.11 & 1449 & 83.9 \\
S4 & 8463 & 1753 & 20 & 140 & 20 & 0.6 & 0.3 & 1.0 & 1.0 & 0.65 & 0.16 & 2506 & 34.5 \\
S5 & 11284 & 1753 & 20 & 140 & 20 & 0.6 & 0.4 & 1.0 & 1.0 & 0.65 & 0.13 & 1967 & 61.1 \\
S6 & 14105 & 1753 & 20 & 140 & 20 & 0.6 & 0.5 & 1.0 & 1.0 & 0.65 & 0.10 & 1619 & 96.0 \\
S7 & 9901 & 2045 & 20 & 146 & 20 & 0.7 & 0.3 & 1.0 & 1.0 & 0.78 & 0.15 & 2721 & 38.1 \\
S8 & 13201 & 2045 & 20 & 146 & 20 & 0.7 & 0.4 & 1.0 & 1.0 & 0.78 & 0.12 & 2136 & 67.5 \\
S9 & 16501 & 2045 & 20 & 146 & 20 & 0.7 & 0.5 & 1.0 & 1.0 & 0.78 & 0.10 & 1759 & 106.1 \\
S10 & 11338 & 2338 & 20 & 152 & 20 & 0.8 & 0.3 & 1.0 & 1.0 & 0.93 & 0.14 & 2890 & 41.0 \\
S11 & 15118 & 2338 & 20 & 152 & 20 & 0.8 & 0.4 & 1.0 & 1.0 & 0.93 & 0.11 & 2269 & 72.7 \\
S12 & 18897 & 2338 & 20 & 152 & 20 & 0.8 & 0.5 & 1.0 & 1.0 & 0.93 & 0.09 & 1869 & 114.2 \\
\hline
\end{tabular}




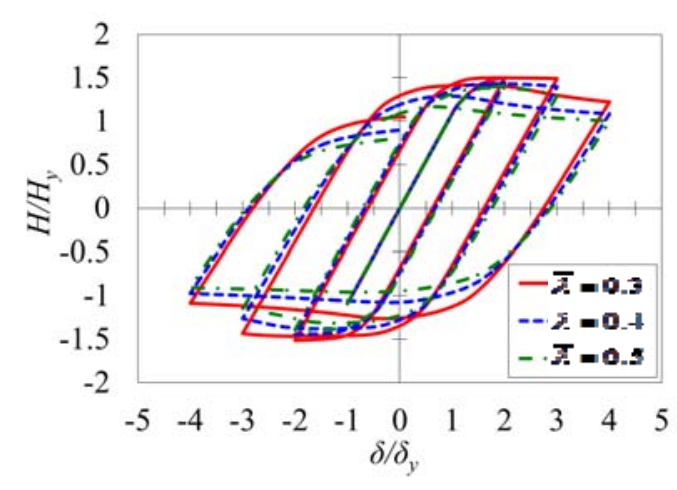

(a) $\mathrm{S} 1 \sim \mathrm{S} 3\left(R_{f}=0.5\right)$

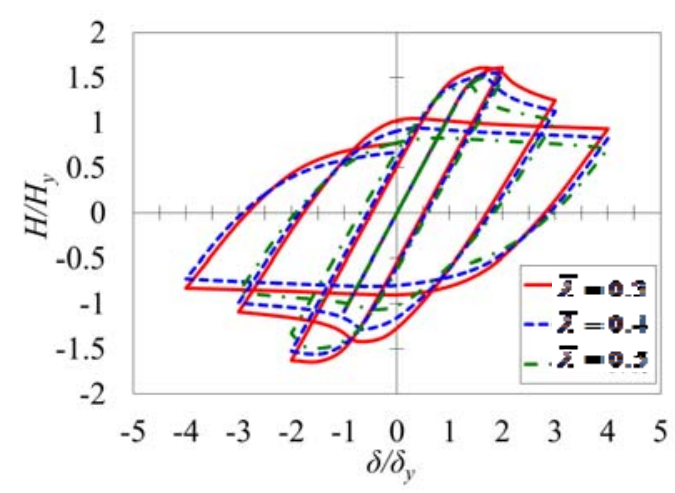

(c) $\mathrm{S} 7 \sim \mathrm{S} 9\left(R_{f}=0.7\right)$

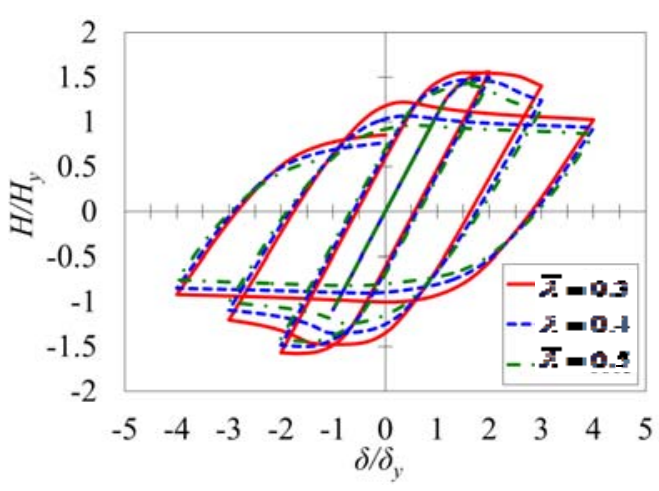

(b) $\mathrm{S} 4 \sim \mathrm{S} 6\left(R_{f}=0.6\right)$

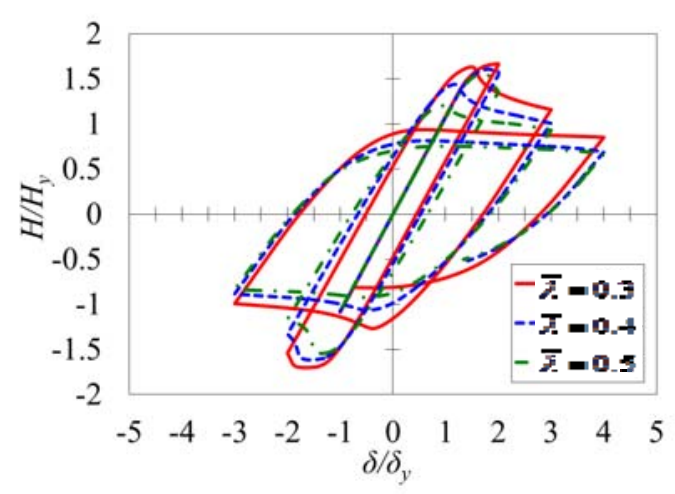

(d) $\mathrm{S} 10 \sim \mathrm{S} 12\left(R_{f}=0.8\right)$

Figure 7. Lateral Load versus Lateral Displacement Curves

\section{SIMPLIFIED SEISMIC EVALUATION METHOD}

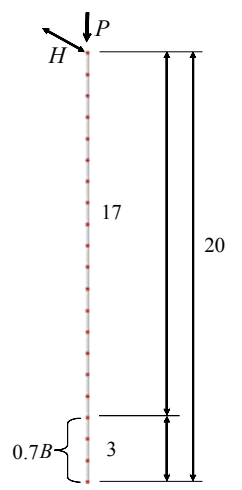

Figure 8. Beam Element Based Model

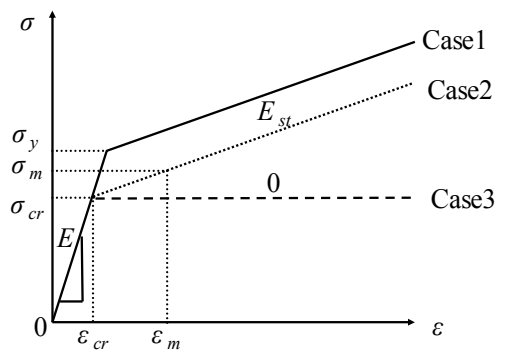

Figure 9. Modified Stress-strain Relationship

The pushover analysis method based on the fiber-beam element is proposed to evaluate the hysteretic behavior of the thin-walled stiffened box piers. As shown in Figure 8, this model has 20 elements and the part with the height of $0.7 B$ from the base, where the local buckling occurred, was divided by 3 . As mentioned above, the effect of the local buckling cannot be considered in the beam element. Therefore, further modification of the bilinear material model is suggested.

As shown in Figure 9, two additional stress-strain relationships are given. Case 1 is a bilinear stress-strain relationship employed in the previous shell element based simulation. In case 2, the yield stress, $\sigma_{y}$, was replaced by the buckling stress, $\sigma_{c r}[12]$, which can be determined by, 


$$
\frac{\sigma_{c r}}{\sigma_{y}}= \begin{cases}1.5-R_{f} & \left(R_{f}>0.5\right) \\ 1 & \left(R_{f} \leq 0.5\right)\end{cases}
$$

Because of the same initial Young's modulus, the buckling strain, $\varepsilon_{c r}$, can be calculated from $\sigma_{c r} / E$. Furthermore, the post-yield modulus, $E_{s t}$, can be given by,

$$
E_{s t}=\frac{\sigma_{m}-\sigma_{c r}}{\varepsilon_{m}-\varepsilon_{c r}}
$$

where $\sigma_{m}$ and $\varepsilon m$ are the local buckling stress and strain, respectively. The local buckling stress, $\sigma_{m}$, can be obtained from the following empirical formula [1],

$$
\frac{\sigma_{m}}{\sigma_{y}}=1.24-0.54 R_{f} \leq 1.0
$$

and the local buckling strain, $\varepsilon m$, is defined in this study as,

$$
\varepsilon_{m}=2 \cdot \frac{\sigma_{c r}}{\sigma_{y}} \cdot \varepsilon_{y}
$$

According to the above-mentioned equations, the material parameters of Case 2 for the different $R_{f}$ are listed in Table 4. It should be noted that in the case of $R_{f}=0.5$, calculated value from Eq. 12 is $\sigma_{m}$ $=304.58<\sigma_{y}=314 \mathrm{MPa}$. In such a case, it is assumed to be the same as Case 1. Moreover, In Case 3 , after the buckling stress point, it yields under the constant stress.

Table 4. Material Parameters of Case 2

\begin{tabular}{cccccc}
\hline$R_{f}$ & $\sigma_{c r}(\mathrm{MPa})$ & $\varepsilon_{c r}\left(\times 10^{-3}\right)$ & $\sigma_{m}(\mathrm{MPa})$ & $\varepsilon_{m}\left(\times 10^{-3}\right)$ & $E / E_{s t}$ \\
\hline 0.5 & 314 & 1.52 & - & - & 100 \\
0.6 & 282.6 & 1.37 & 287.6 & 2.74 & 56.25 \\
0.7 & 251.2 & 1.22 & 270.7 & 2.44 & 12.90 \\
0.8 & 219.8 & 1.07 & 253.7 & 2.13 & 6.48 \\
\hline
\end{tabular}

\section{NUMERICAL COMPARISON}

As described before, three bilinear stress-strain relationships were employed for the fiber-beam elements in the pushover analysis method. Figure 10 compared the horizontal force versus the horizontal displacement relationships of some numerical cases. The yield lateral load, $H_{y}$, and the yield lateral displacement, $\delta y$, were employed to make these curves dimensionless. Besides, the skeletons of the hysteretic relationships of the shell element-based simulation were given together. It can be seen that, from Case 1 to Case 2 and then to Case 3, the force-displacement curve moved downward.

The ultimate points were assumed as the maximum strength and 95 percent of the maximum strength after the peak, respectively. Moreover, the authors suggested Eqs. 14 and 15 for calculating the ultimate compression strain $\varepsilon_{m}$ (strain corresponding to the maximum bending moment $M_{\max }$ ) and $\varepsilon_{u}$ (strain corresponding to $95 \% M_{\max }$ after peak) achieved by the simulation of the stiffened box section under the compression and bending (Zheng et al. [13]). 


$$
\begin{aligned}
& \frac{\varepsilon_{m}}{\varepsilon_{y}}=\frac{1.41}{\left(R_{f} \bar{\lambda}_{s}^{0.18}-0.21\right)^{0.462}}+0.38 \leq 20.0 \\
& \frac{\varepsilon_{u}}{\varepsilon_{y}}=\frac{0.7}{\left(R_{f} \bar{\lambda}_{s}^{0.18}-0.18\right)^{1.3}\left(1+P / P_{y}\right)^{2.2}}+\frac{3.2}{\left(1+P / P_{y}\right)} \leq 20.0 \\
& \left(0.3 \leq R_{f} \leq 0.8, \quad \gamma / \gamma^{*} \geq 1.0, \quad 0.0 \leq P / P_{y} \leq 0.5\right)
\end{aligned}
$$

The average strain of the outmost brink center of the three elements at the base, located on the effective failure length, is defined as $\varepsilon a v g$. When $\varepsilon a v g$ reaches $\varepsilon m$ and $\varepsilon u$, the corresponding displacements are defined as the ultimate displacements, $\delta_{m}$ and $\delta_{u}$, respectively. In terms of the force-displacement curve, the corresponding forces are defined as the ultimate strengths, $H_{m}$ and $H_{u}$, respectively. The required ultimate points $\left(\delta_{m}, H_{m}\right)$ and $\left(\delta_{u}, H_{u}\right)$ are shown in Figure 10 . The comparisons of the ultimate points between the fiber-beam based model and the shell based model are shown in Figures 11 and 12.

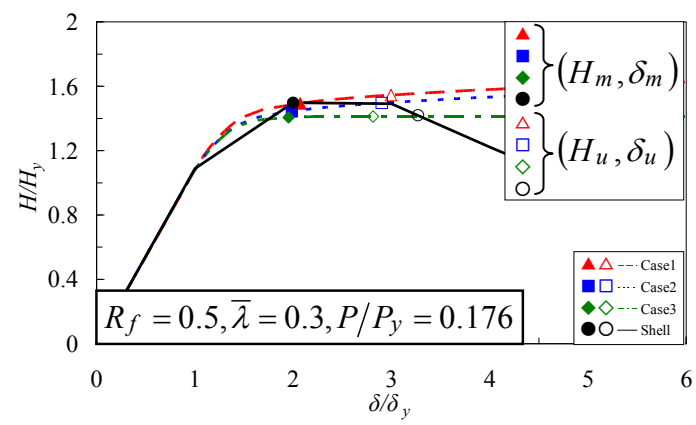

(a) S1

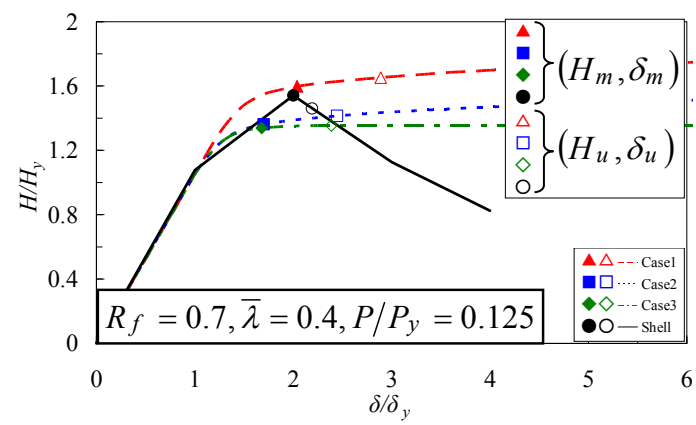

(c) $\mathrm{S} 8$

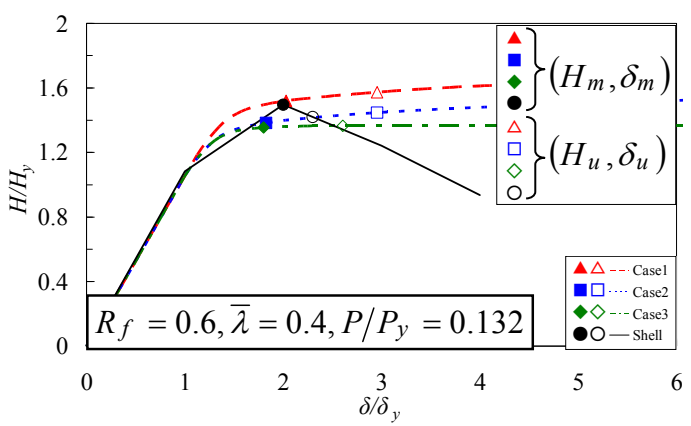

(b) S5

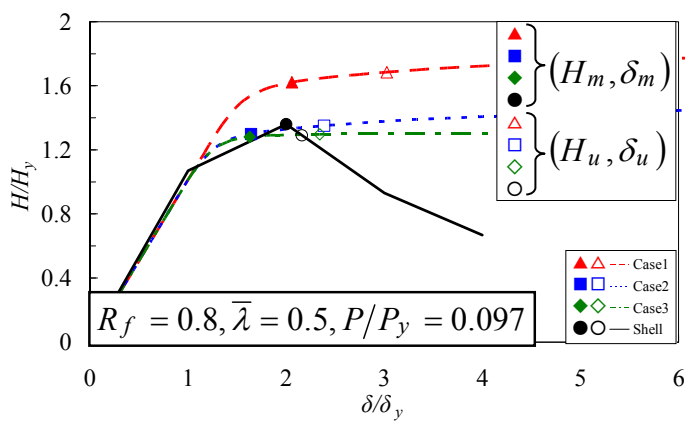

(d) S12

Figure 10. Comparison of Ultimate Values

Figures 11(a), 11(c) and 11(e) compare $H_{m}$. When Case 1 is used as the fiber-beam's material model, the deviations of eleven cases are below $10 \%$, but the results of the fiber-beam based model are relatively larger than those of the shell based model (in the dangerous side). When Case 2 is employed, the deviations of all cases are below $20 \%$ and the results of the fiber-beam based model are in the safe side. Furthermore, Case 3 seems safe in comparison with Case 2, but the deviations of two cases are over 20\%. Figures 11(b), 11(d) and 11(f) compare $\delta_{m}$. The deviations of twelve cases employing Case 1 are all below 10\%. On the other hand, although the deviations exceed 20\% for the cases using either Case 2 or Case 3, both are confirmed safe.

Figures 12(a), 12(c) and 12(e) compare $H_{u}$. When Case 1 is used, the deviation of one case exceeds $20 \%$ and the others approach the $10 \%$ line, but the results of the fiber-beam based model are 
relatively large and locate in the dangerous side. When Case 2 is used, the deviations of all the cases are below $20 \%$ and the results are slightly large. When Case 3 is used, although the deviations of the two models exceed $20 \%$, the results are in the safe side. Figures 12(b), 12(d) and 12(f) compare $\delta_{u}$. When Case 1 is used, the deviations of six models exceed $20 \%$ and the results are relatively large. When Case 2 is used, the estimation accuracy was improved and the deviations were below $20 \%$ for all models. The accuracy of estimation is further improved for Case 3 .

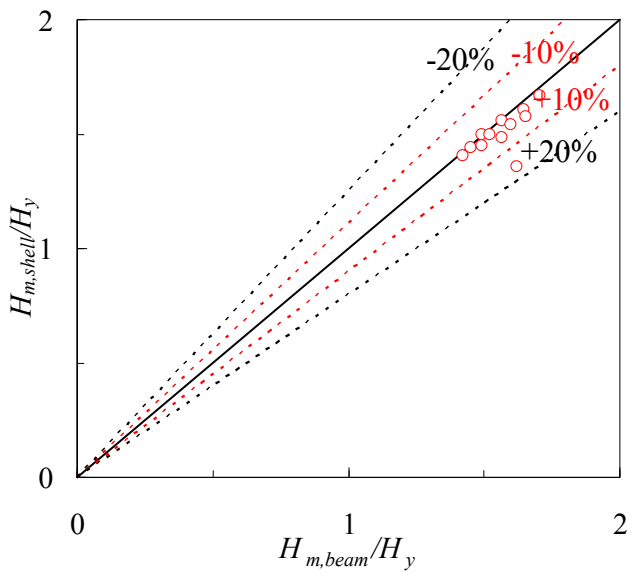

(a) Case 1

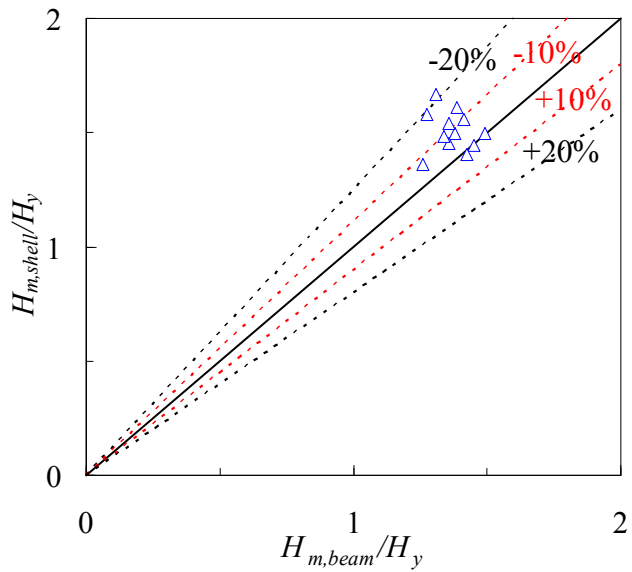

(c) Case 2

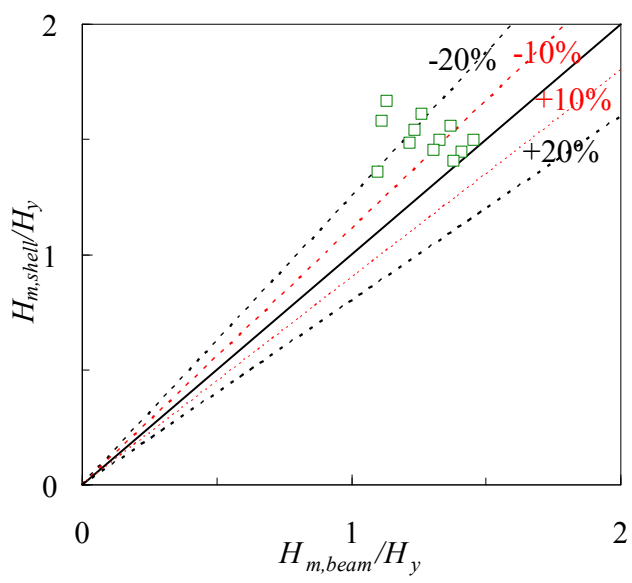

(e) Case 3

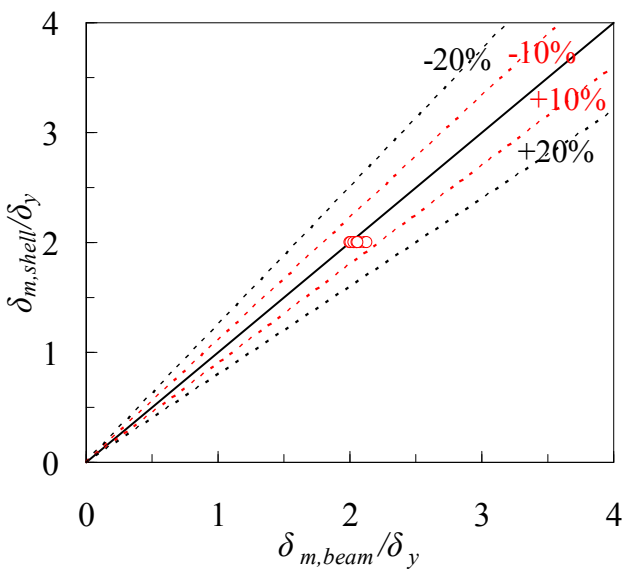

(b) Case 1

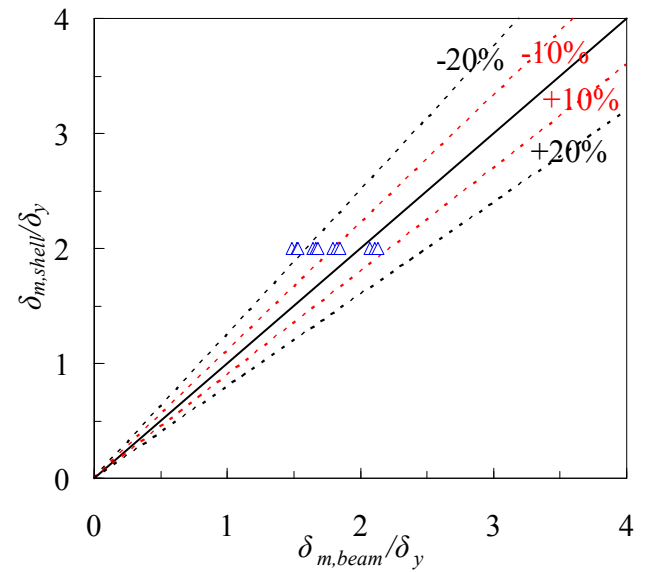

(d) Case 2

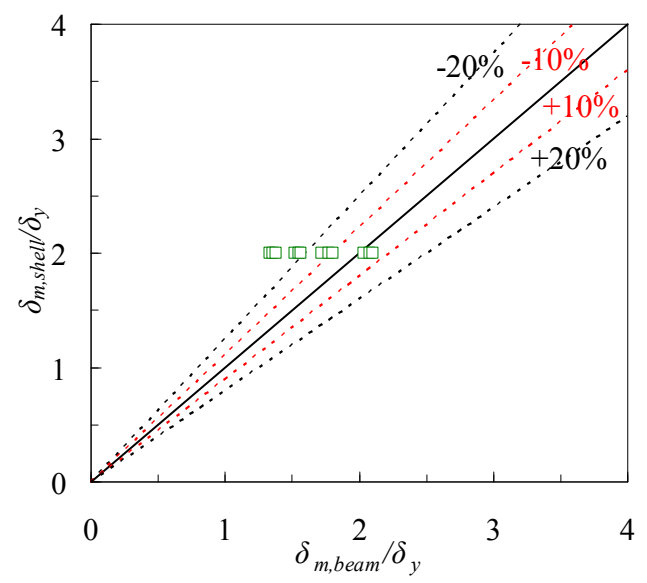

(f) Case 3

Figure 11. Comparisons of $H_{m}$ and $\delta_{m}$ 


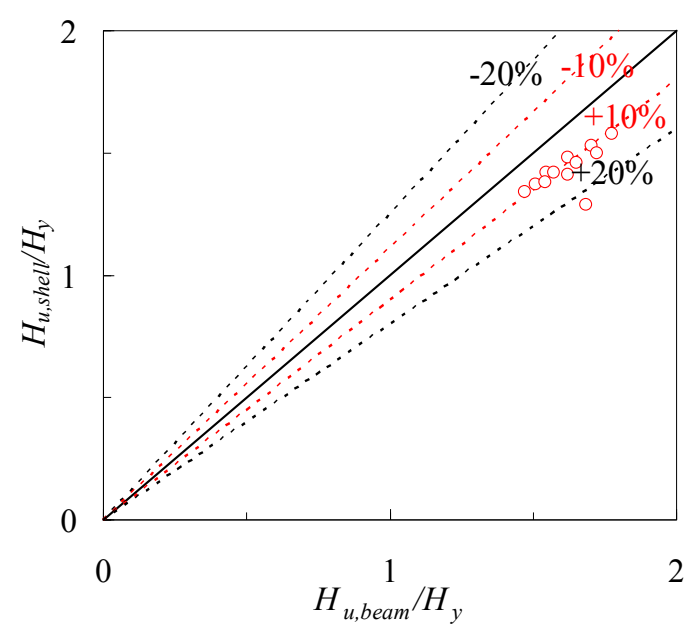

(a) Case 1

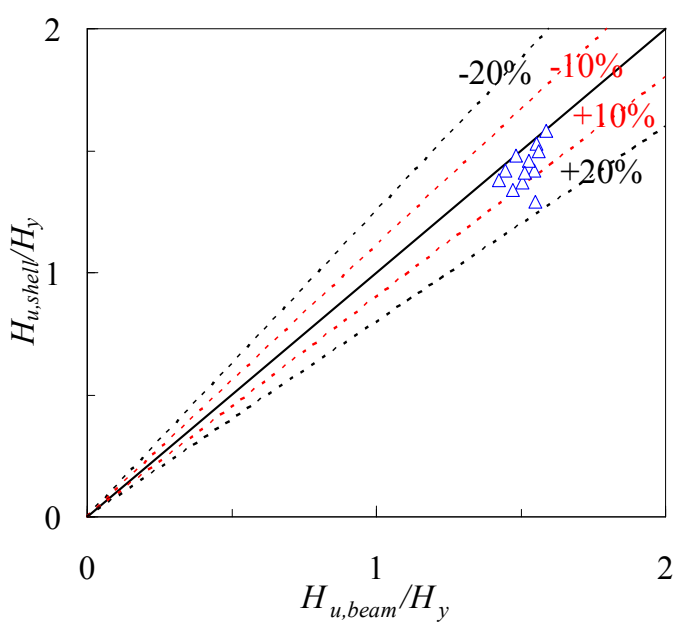

(c) Case 2

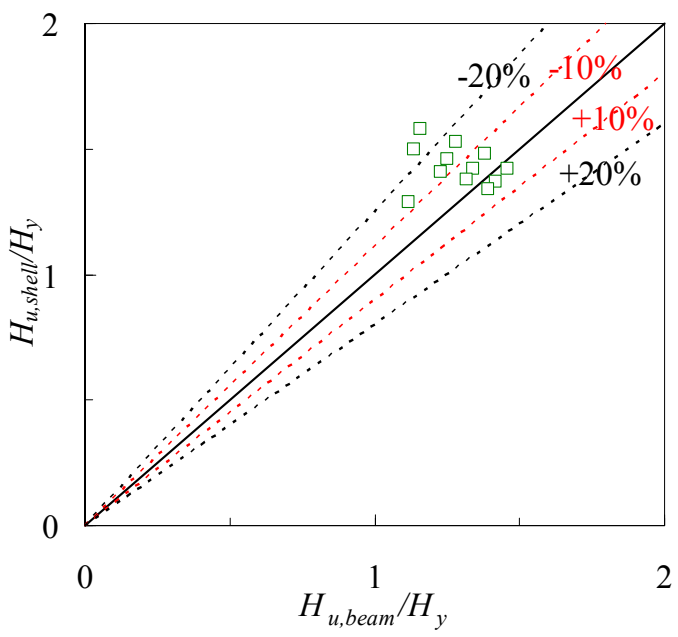

(e) Case 3

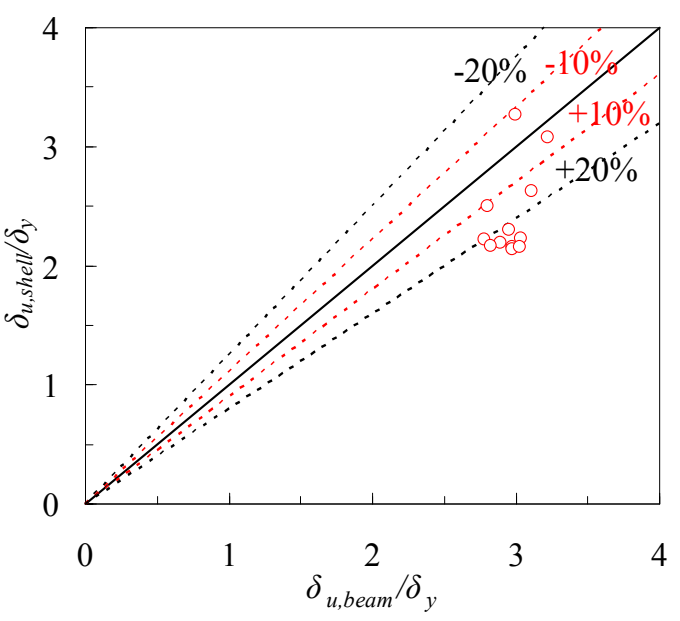

(b) Case 1

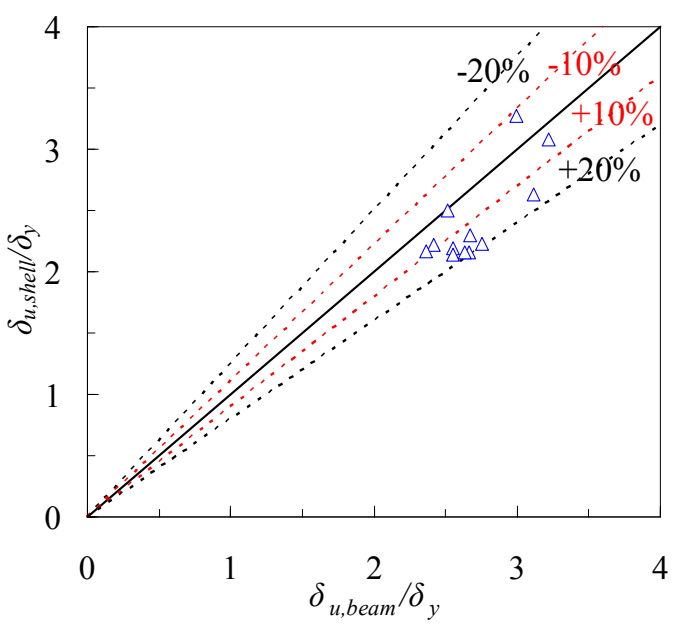

(d) Case 2

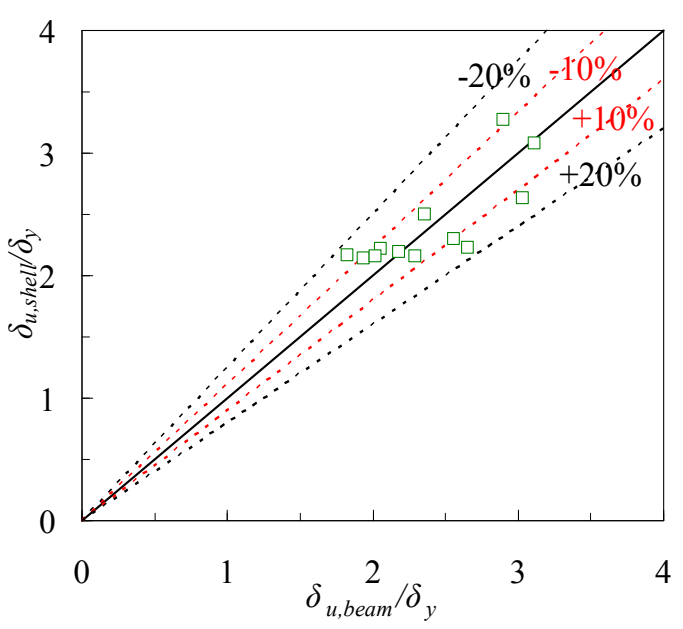

(f) Case 3

Figure 12. Comparisons of $H_{u}$ and $\delta_{u}$ 
From Figures 11 and 12, the results achieved by using Case 2 are optimal when the maximum strength is taken as the ultimate point. On the other hand, the results achieved by using Case 3 are optimal when the $95 \%$ of the maximum strength after peak is regarded as the ultimate point.

\section{CONCLUSIONS}

The conclusions of this study can be given: (1) it's confirmed that the shell element based model employing the bilinear kinematic hardening relation can effectively reflect the thin-walled stiffened box steel piers; (2) Strength and ductility of thin-walled stiffened box sectional steel bridge piers can be accurately predicted using the proposed pushover method based on the fiber-beam element. it is advised to adopt the modified bilinear material model (Case 2), in which the yield point is replaced by the buckling stress, when the maximum strength is taken as the ultimate point; and (3) in addition, it is advised to adopt the elastic-perfectly plastic material model (Case 3 ) when the 95\% of the maximum strength after the peak is regarded as the ultimate point in the proposed method.

\section{ACKNOWLEDGEMENTS}

The study was supported by Science and Technology Research Project of Ministry of Transport, PRC (No.2011 318775 680) and the Transportation Foundation of Henan Province, PRC (No.2011GF11).

\section{REFERENCES}

[1] Usami, T. and Ge, H.B., "Cyclic Behavior of Thin-Walled Steel Structures - Numerical Analysis", Thin-Walled Structures, 1998, Vol. 32, pp. 41-80.

[2] Ge, H.B., Gao, S. and Usami, T. "Stiffened Steel Box Columns. Part 1: Cyclic Behavior", Earthquake Engineering and Structural Dynamics, 2000, Vol. 29, No. 11, pp. 1691-1706.

[3] Usami, T., Gao, S. and Ge, H.B., "Stiffened Steel Box Columns. Part 2: Ductility Evaluation", Earthquake Engineering and Structural Dynamics, 2000, Vol. 29, No. 11, pp. 1707-1722.

[4] Susantha, K.A.S., Aoki, T., Kumano, T., Yamamoto, K., "Applicability of Low-yield-strength Steel for Ductility Improvement of Steel Bridge Piers", Engineering Structures, 2005, Vol. 27, No. 7, pp. 1064-1073.

[5] Galambos, T.V., "Guide to Stability Design Criteria for Metal Structures (5 $5^{\text {th }}$ edn)", Wiley, 1998.

[6] Gao, S., Usami, T. and Ge, H.B., "Ductility evaluation of steel bridge piers with pipe-sections", Journal of Engineering Mechanics, ASCE, 1998, Vol.124, No.3, pp.260-267.

[7] Goto, Y., Wang, Q. and Obata, M., "FEM Analysis for Hysteretic Behavior of Thin-Walled Steel Columns", Journal of Structural Engineering, ASCE, 1998, Vol. 124, No. 11, pp. 1290-1301.

[8] Sakimoto, T., Watanabe, H. and Nakashima, K., "Hysteretic Models of Steel Box Members with Local Buckling Damage", Journal of Structural Mechanics and Earthquake Engineering, JSCE, 2000, Vol. 647, No. I-51, pp. 343-355. (in Japanese)

[9] Ozawa K., Wang Q. and Goto Y., "A Pushover Analysis of Steel Piers Based on a Beam Element with a Softening Constitutive Relation Considering the Localization of Buckling Patterns in Stiffened Plate Components", Journal of Structural Mechanics and Earthquake Engineering, JSCE, 2001, Vol. 689, No. I-57, pp. 225-237. (in Japanese) 
[10] Nishikawa, K., Yamamoto, S., Natori T., Terao, O., Yasunami, H. and Terada, M., "An Experimental Study on Improvement of Seismic Performance of Existing Steel Bridge Piers", Journal of Structural Engineering, JSCE, 1996, Vol. 42A, pp. 975-986.

[11] Usami, T., Mizutani, S., Aoki, T. and Itoh, Y., "Steel and Concrete-filled Steel Compression Members under Cyclic Loading." In: "Stability and Ductility of Steel Structures under Cyclic Loading." CRC Press, 1992, pp. 123-138.

[12] JRA, "Specifications for Highway Bridges, Part I: Common and Part II: Steel Bridges", Japan Road Association, Tokyo, Japan, 2012. (in Japanese)

[13] Zheng, Y., Usami, T. and Ge, H.B., "A Seismic Design Methology for Thin-Walled Steel Structures through the Pushover Analysis." NUCE Research Report, No.2000-01, Nagoya University, 2000. 